\title{
Challenges of Executive Information Systems in listed Johannesburg Stock Exchange companies
}

\author{
Authors: \\ Elmarie Papageorgiou ${ }^{1}$ \\ Herman de Bruyn² \\ Affiliations: \\ ${ }^{1}$ School of Accountancy, \\ University of the \\ Witwatersrand, South Africa \\ ${ }^{2}$ Department of Business \\ Management, University of \\ Johannesburg, South Africa \\ Correspondence to: \\ Elmarie Papageorgiou \\ Email: \\ Elmarie.Papageorgiou@wits. \\ ac.za \\ Postal address: \\ Private Bag 3, Wits 2050, \\ South Africa

\section{Dates:} \\ Received: 30 July 2010 \\ Accepted: 17 May 2011 \\ Published: 05 Sept. 2011 \\ How to cite this article: \\ Papageorgiou, E. \& \\ De Bruyn, H., 2011, \\ 'Challenges of Executive \\ Information Systems in \\ listed Johannesburg Stock \\ Exchange companies', SA \\ Journal of Information \\ Management 13(1), Art. \\ \#448, 10 pages. doi:10.4102/ \\ sajim.v13i1.448
}

(C) 2011. The Authors.

Licensee: AOSIS

OpenJournals. This work

is licensed under the

Creative Commons

Attribution License.
Background: The widespread use of Executive Information Systems (EISs) as a management information tool was noted in listed Johannesburg Stock Exchange (JSE) companies. The digital business environment exposed executives to so much data that data need to be converted into useful information that is organised and summarised.

Objectives: The purpose of this study is to establish and to determine the existence, and to what extent EISs exist in all levels of management and to identify the challenges companies experienced in listed JSE companies. Therefore the problem exists that EIS-users at all levels of management are unaware of the challenges of EISs and that EISs can be used as a tool to analyse their businesses' performance and competitiveness.

Method: A mixed method was used; both quantitative and qualitative in nature. Questionnaires were sent to 334 listed JSE companies and 13 interviews were conducted with users of EISs in all levels of management.

Results: The results of the study demonstrate that the majority of respondents of the questionnaire have an EIS or plan to implement an EIS. The results further revealed the respondents' positive attitude towards EISs as it is an excellent management information tool that adds strategic value to their business, that is critical for real-time decision-making, solves problems and creates a competitive edge. From the results it is evident that there is a need for an EIS to be 'everybody's information system'. The results of the interviews demonstrate that an EIS is a seamless reliable system necessary for proper timeous decision-making. The respondents to the questionnaire and the interviewees indicated that they understood the value of EISs as a useful part of their company.

Conclusion: The study adds value to the awareness and understanding of EISs that creates a business environment in which business and management can enhance sustainability and strategic competitiveness.

\section{Introduction and background}

Executive Information Systems (EISs) were originally developed solely for executives' use in businesses in the late 1980s (Martin, Dehayes, Hoffer \& Perkins 2005:223) and caused many problems with regard to data disparity between the layers of the business. Traditionally it was the responsibility of lower management levels to deal with internal data and to know what was reported to the top executive level, but nowadays the base has been broadened to encompass all levels of management.

Nichols (1990:17) concluded that ' ... greater use would be in the designing of information systems for decision-making in the whole business' and that '... general functions of information systems are to determine user needs'. But Friend (1992:328) was the first to suggest a name change that an EIS ought to be '... everybody's information system ...' as an EIS is defined as '... an information system for executives ...' only. Wheeler, Chang and Thomas (1993:182) experience an EIS differently: '... an EIS failed as a system for senior executives, since it was almost certainly not appropriate for them in the first place'. However, the EIS did supply lower level staff with vital corporate information. Ikart (2005:78) suggests that there is a higher degree of EISs usage by middle managers than top-level managers. Businesses are therefore faced with an even bigger challenge: the emergence of EISs in all levels of the business.

Definitions of an EIS vary and 20 different studies (Arnott, Jirachiefpattana \& O'Donnell 2007:2078; Averweg \& Roldán 2006:626; Bajwa, Rai \& Brennan 1998:31; Bergeron, Raymond, Rivard \& Gara 1995:131; Boci, Chaffey, Greasley \& Hickie 2003:257; Byrd \& Marshall 1996:449; Elam \& Leidner 1995:89; Frolick \& Robichaux 1995:157; Khan 1996:16; Martin, Dehayes, Hoffer \& 
Perkins 2005:223; Nord \& Nord 1995:96; Olson \& Courtney 1992:217; Pijpers, Bemelmans, Heemstra \& Van Montfort 2001:960; Rainer \& Watson 1995:147; Remenyi 1991:48; Salmeron 2002:111; Sterrenberg 1990:32; Turban, Mclean \& Wetherbe 1996:42; Xu \& Kaye 2002:81; Young \& Watson 1995:153) were investigated to define an EIS. The different definitions of an EIS of the 20 studies were compared and evaluated amongst each other. Most of the studies included the internal and external environment, explained the kind of information to be used, to make decisions, to solve problems and included executives and top management as the main users; however, only a few of the studies mentioned how to display the information to users. For the purpose of this study an EIS can be defined as a computerised system that provides executives, top management and other senior managers with access to internal and external information; in short, information that is relevant, accurate, timely and up-to-date in order to make decisions, solve problems, determine critical success factors and satisfy information needs. These interest groups are primarily interested in summarised data that has been transformed into meaningful information, through the use of graphs, reports and on-line screens.

EISs function effectively in dynamic business conditions and are used in the most intensely competitive environment of businesses. Executives need to develop skills to respond to and to understand how to interact with the global environment that will eventually increase the value of the business and the value of the shareholder.

\section{Purpose of the study and research question}

The purpose of the study was to establish and to determine the existence and to what extent EISs exists in all levels of management and to identify the challenges companies experienced in listed JSE companies. This is demonstrated by an elucidation of business concepts for understanding an EIS and major challenges of EISs in listed JSE companies. The research question is to establish what the existence of EISs is to create awareness amongst EIS-users in understanding the challenges presented by EISs in listed JSE companies to compete successfully in a global environment.

\section{Literature study}

The literature study investigates the business concepts for understanding EISs and the challenges presented by EISs in listed JSE companies.

\section{Business concepts for understanding Executive Information Systems}

The challenges presented by an EIS are discussed and examined in the context of three business concepts, namely:

1. information

2. decision-making

3. the business environment.

\section{Information}

According to Hall (2007:21), '... the value of information to a user is determined by its reliability'. When all attributes and qualities are consistently present, information has reliability and adds value to the user. Unreliable information and information with no value may lead to wrong decisions, affect the performance of the business and may ultimately threaten the survival of the business. Meyer (2005) argues that information comes in many different forms and businesses need to investigate how to deal with relevant and discarded information: archive it or delete it. Another type of information that is highly significant and useful for executives is soft information, such as rumours, ideas, opinions and explanations, (Byrd \& Marshall 1996:456) that is less structured than hard information, such as numbers, graphs and tables, and is often more difficult to store and retrieve in a computerised system. According to Boone and Kurtz (2006:490), '... information is the final frontier of organisations seeking to gain an edge over their competitors ...' and therefore management needs information and technology to manage their businesses successfully. Information systems assist the business to organise the overwhelming flood of information in a logical and accessible manner. Users need to be exposed to information to establish a connection between the business and the environment (Correia \& Wilson 1997).

According to Boone and Kurtz (2006:490), you can give people responsibility and authority, but without any information they are helpless. For any information to be efficient and effective, and to add value and knowledge to the business, the information needs to be controlled and managed in the business. An information overflow can provide too much data for management to absorb and thus become irrelevant for decision-making. Paradoxically, too little information may also jeopardise the ability of management to make decisions. Information not only provides top management with direct access to information, but is also accessed or is filtered through to lower levels of management. Lower levels of staff are not always able to recognise the importance of information and in some cases pass the information on without interpreting its relevance and/or without consolidating and understanding the potential of the information. According to Martin, Dehayes, Hoffer and Perkins (1994:38), most successful EISs '... are available in consistent detail to all levels ...' in businesses and are still valid today; according to Averweg and Roldán (2006:632), 'the most important EIS groups are top functional managers and middle managers'. Therefore the value of information is also increased '.. by providing rapid access to critical information' (Arnott et al. 2007:2078) to senior and middle management. Bocij et al. (2003:5) supplies several definitions of information that provide information in systems:

- data that have been processed that is meaningful

- data that have been processed for a certain purpose

- data that have been interpreted and understood by the recipient.

Bocij et al. (2003:37) define a system as '... a collection of interrelated components that work together towards a 
collective goal'. In all businesses the primary goal is to make a profit or to improve the quality of a product or a service. All systems in a business context receive inputs that need to be transformed into outputs.

\section{Decision-making}

Management is a series of decision-making processes. According to Averweg and Roldán (2006:625), an '... EIS is a computer-based technology designed in response to the specific needs of executives and for making both strategic and tactical decisions'. Therefore strategic and significant decisions need to be made quickly and accurately in a short period of time in order to solve problems effectively and efficiently. Mintzberg (1975:56) includes the information role as one of the managerial roles that incorporate monitoring, filtering and disseminating of information as a universal part of management and is still true today, according to Averweg and Roldán (2006:631), who state that 'one of the capabilities of an EIS is the filtering, organisation and consolidation of multiple data sources'.

Lessing and Scheepers (2004:23) state that communicating information to decision-makers is the most important function of the business. On the other hand Mintzberg and Waters (1990:4) argue that the concept of decision-making has outlived its usefulness and there are situations where actions are taken by management without decisions being made. Over the past few years several businesses confirmed the value of 'gut' feeling when management decisions are optimally made and realistic decision-making is based on existing data, which can be solved by the application of computer technology (Van Zyl 2010:12). According to Naicker (2010:21), decisions are based on the information available to users. Sourcing relevant and accurate information ensures that the decision making process encompasses all the aspects of the business and future trends. Averweg and Roldán (2006:626) stated that definitions of an EIS varied between different studies but all identify the need for information that supports decisions about the business as the most important reason for the existence of an EIS.

\section{Business environment}

Wessels (2008:148) states that advances in information technology have been identified as a key driver that affects the business environment. According to Typanski (1999:32), if an information environment is to be truly effective '... its resources must be managed so that they are in synch ...' with the overall business goals and strategies. The business is influenced by certain elements that affect the way in which it operates and is surrounded by the business environment. A new concept added to the business environment is the influence of e-business that involves the increasing efficiency of information flow, both within the business and with external sources. E-business supports business processes and is continually updating the external environment in order for managers to extract information in real-time to make decisions and solve problems. According to Averweg and Roldán (2006:632), an 'EIS is going through a major change to take advantage of Web-based technologies in order to satisfy information needs of an increasing group of users'.

\section{Challenges of an Executive Information System}

The challenges of an EIS may influence the implementation of an EIS in a business; 14 challenges of an EIS are identified in Figure 1 and are discussed in the next section. In context with the different challenges the 'input of data', streams of raw facts representing events occurring in the business before they have been organised and arranged into a form people can understand them, to be converted into 'output of information', data that have been shaped into a form that is meaningful and useful to human beings, in a business environment making decisions to provide feedback on a regular basis to solve problems. Persons at all levels need to feel that they have a role to play in the achievement of strategy and need feedback on their progress (Meyer 2011:50). One area, managing the everyday budget expenses of management, yields really fast benefits from real-time systems as the information needs to be fast, relevant, realtime, accessible and easy to understand (Phillips 2011:37).

\section{Global environment}

A global environmental analysis in which the EIS operate is conducted in such a way that it influences the way in which the business attains their overall goals (Bocij et al. 2003:519). Lessing and Scheepers (2004:14) define the environment as '... people and organisations'. Braman (1989:239) defines information in context with the global environment, as '... information that is not just affected by its environment, but is itself a factor affecting other elements in the environment'. Palvia, Kumar, Kumar and Hendon (1996:177) argue that businesses need to incorporate a global and international dimension in the design of EISs in global businesses in a global environment in order to conduct business and compete globally. Prokesch (2000:69) believes that all businesses are battling it out in the global information environment and facing common challenges like using knowledge more effectively than their competitors do.

\section{Strategy of the business}

Globalisation has forced South African businesses that wish to survive or to perform in a global environment, to consider a management information system as a strategic management information tool to achieve objectives within a specified time period (Nieman \& Bennett 2002:376). Strategy development is strongly influenced by the environment the business operates in (Bocij et al. 2003:519). A combination of strategy and management processes is delivered through an EIS, which raises the standard of management performance for executives, management and users to ensure sustainability and strategic competitiveness for the business. 'Executing strategy successfully requires making tough, often uncomfortable choices based on simple logic and clear principles' (Simons 2010:100) as the road to success is to engage in emerging data and eventually in action plans. Porter (1996:64) states that the '... essence of strategy is in the activities - choosing to perform activities differently 


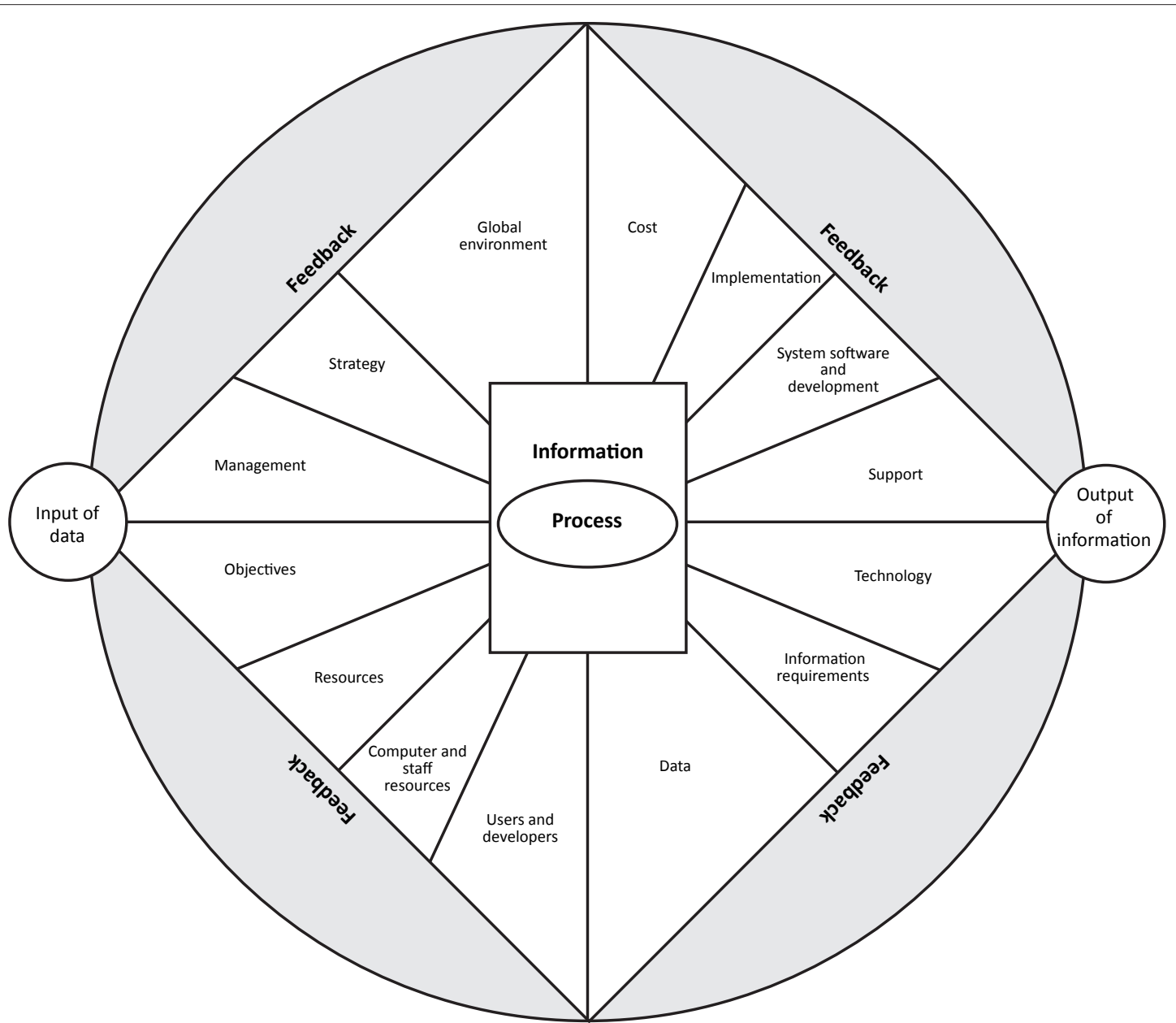

Source: Adapted from Boddy, D., Boonstra, A. \& Kennedy, G., 2005, Managing information systems: An organisational perspective, 2nd edn., Pearson, Harlow, UK.

FIGURE 1: Challenges in an Executive Information System in context.

or to perform different activities than rivals'. In one of the studies, Pitts and Lei (2003:7) define strategy as '... referring to the ideas, plan, and support that firms employ to compete successfully against their rivals'.

Businesses need to know how to compete and to build a competitive advantage over their competitors. There is tension between an internal and external focus; on the one hand the focus is on external strategy in terms of positioning the business in its environment. On the other hand, the focus is on the extent to which it is able to be dependent on the internal capabilities and strategies of the business (Meyer 2011:51). Pitts and Lei (2003:7) argue that '... strategy is designed to help firms achieve competitive advantage'. To strategically position the business to be competitive is often not obvious nor an easy task and to position the business correctly requires creativity and insight by management. According to Burgelman and Doz (2004:118), new positions become available because of change; for example, new customers, distribution channels and new techniques.

\section{Management of the business}

Burgelman and Doz (2004:1181) state that the unique role of top management is the task of '... developing a strategy-making process that can balance the challenges associated with exploiting existing and new opportunities simultaneously'. Senior management owns a fiduciary responsibility to their stakeholders to ensure the business delivers value to its shareholders, the owners of the business (Pitts \& Lei 2003:21). Management and senior executives need to be motivated and committed to influence their employees and to develop strategies that add value to the business and remain competitive in the industry (Stephenson 1986:33). If management do not commit and dedicate themselves, the result is poor management and a lack of control and direction. Voogt (2010:28) states that the role of the Chief Information Officer (CIO) has changed dramatically over the past few years. This as a result of the fact that the skills of the Chief Financial Officer (CFO) addressing IT risk strategically and understanding the impact of IT across all business functions will be invaluable in addressing IT governance.

\section{Objectives of the business}

Hall (2007:16) suggests three fundamental objectives that are common to all information systems. They are:

- to support the responsibility function of management

- to support management decision-making

- to support the business's day-to-day activities. 
Objectives or goals are set during the design phase of a new system and stipulate what the system is responsible for, and how the system will contribute in assisting users to perform their tasks. The performance of the business (system) is measured by comparing it to the objectives of the business (Bocij et al. 2003:38). In the South African environment with diverse cultures, languages, religions, races and social backgrounds, personal objectives that may vary from person to person and this may cause conflict and rivalry amongst groups. Managers need to assist employees to solve any conflicts and personal problems in order to help attain the goals and objectives of the employees, which, in turn, will help to attain the goals and objectives of the business, and thus assuring the success of the business.

\section{Combining data of multiple resources: Internal and external}

According to Boone and Kurtz (2006:492), businesses can create their own databases of multiple resources to serve as an input in their information system. Averweg and Roldán (2006:631) stated that there are different types of sources of information that support an EIS, internal and external: corporate databases; operational databases; individuals; external databases; reports; the Internet; intranet and extranet. Watson, Watson, Singh and Holmes (1995:174) state that the top five motivating factors to develop an EIS are internal by nature. The five motivating factors in their rank order are as follows:

1. provide easier, faster access to information

2. improve the efficiency and effectives of senior executives

3. monitor organisational performance

4. improve communication

5. extract and integrate data from incompatible sources.

They continue by stating that the two factors relating to external environment are the '... competitive information ...' and being able to '... monitor the external environment' (Watson et al. 1995:174).

\section{Computer and staff resources}

Watson et al. (1995:174) state that resource requirements are initiated and developed by teams with technical and business skills. The choice of software depends on the type of business and the availability of experienced and committed staff to make the correct choices to suit the needs of their business. Volonino, Watson and Robinson (1995:106) state that a common technology infrastructure drives the EIS and is achieved by customising interfaces and system capabilities. Salmeron (2003:35) argues that in order to develop staff in a business, certain computer, human and information technology resources are required.

\section{Variety, complexity and defining of information requirements}

Watson et al. (1995:173) state that EISs spread, evolve and '... over time, additional users are given access to the system and capabilities are put in place'. Information requirements change as the information technology and global environment change, therefore the variety of information to choose from becomes more complex and copious. Information is complex in the sense that there are so many sources with different versions of data available, that management must implement criteria that defend against the increasing risk from using unreliable sources (Lessing \& Scheepers 2004:184). Frolick and Robichaux (1995:168) conclude that '... executive information requirements are dynamic, in many, perhaps most ...' businesses. They also suggest that successful EIS information requires a thorough examination of the business's input from executives. According to Cheung and Babin (2006:1590), executive users become more computer literate, request more sophisticated information technology support and in many cases take charge of the system development process.

\section{Controversy between users and developers}

Young and Watson (1995:162) suggest that technical staff must be proficient to update EISs, as they change frequently. According to Frolick and Robichaux (1995:168), '... EIS developers must build and maintain a model of executives' information requirements'. There must be a mutual understanding between the specifications and requirements of executives and EIS users in order for developers to interpret the specifications and requirements correctly.

\section{Data}

Information systems need to provide instantaneous and controlled information for multi-user access to common corporate data files on a need-to-know basis (Cash, Mcfarlan \& Mckenney 1992:126). Data is categorised as hard or soft, and internal or external. In contradiction, adhocracy leaders tend to avoid precise data and are more interested in opinions, explanations, written data and verbal stimuli (Byrd \& Marshall 1996:456). The daunting task of management is to coordinate all the data and use well-chosen tools and procedures to ensure effective information systems.

\section{Technology}

'All innovation is now driven by technology in some way' and it is happening much faster (Cramm 2011:124). According to Nord and Nord (1995:102), '... as commercial EIS software improves, top executives must utilise the software technology for strategic decision-making and managing daily business activities in order to be competitive'. Therefore software technology changes constantly and management needs to keep up with the latest technology in order to be competitive. McLeod and Jones (1992:67) state that the use of technology improves the quality of information as computes have the potential to play an important role in the executive's information system. Klenke (1993:214) argues that existing and emerging technologies provide leadership opportunities for IS professionals to expand their role from technical managers to strategic leaders.

\section{Support}

EISs and information systems need technical and information support. Grindley (1991:3) describes the duties and responsibilities of developers and technical staff as 
follows: '... we control the computer. After all, we write the programs. But, once they're up and running we seem to lose the control we thought we had'. Clark (1994:33) states that IS managers are reluctant or unable to employ people to define and develop a variety of specialised systems in a diverse business environment. Watson (1992:242) stresses that '... good EIS support staff is critical'.

\section{Development}

Watson et al. (1995:175) state that '... developing an EIS may require an organisation to enhance its overall computing environment'. Watson et al. (1995:176) argue that there is no generally accepted EIS development life cycle and no agreement by businesses on the sequencing of activities in the life cycle. Byrd and Marshall (1996:462) contend that Chief Executive Officers (CEOs) do not have a great amount of time to devote to the development of systems such as EISs. Singh, Watson and Watson (2002:80) also conclude that the executive time needed to spend time with analysts is a scarce resource as executives get involved in what information is most important for them, how the information can be enhanced, how it should be displayed and how frequent it should be updated (Singh et al. 2002:80).

\section{Implementation}

Studies in the implementation of information systems vary whilst many businesses transform business operations successfully and enhancing business performance, to businesses that fail to meet the specified requirements. Boddy et al. (2005:223) state that businesses that operate in a volatile environment motivate competing businesses to implement new processes. People need to change the way they work and be willing to make significant technical and organisational changes.

\section{Cost}

Watson et al. (1995:175) state that '... EISs tend to be expensive' as $19 \%$ of the business's EIS are built in-house compared to $60 \%$ of businesses that rely exclusively on off-the-shelf software. Money is mostly wasted on market research, personnel cost and seeking suitable EIS software to implement. On the other hand many advantages of implementing EISs relating to cost are put forward such as low marketing and advertising cost, lower communication cost and lower printing and stationery cost.

\section{Research design and methodology}

The research study used a mixed method design that is quantitative and qualitative in nature. Questionnaires and interviews were used to collect data. The exploration proceeded in three stages: firstly, questionnaires were used to determine the status quo and the existence of EISs in businesses; secondly, interviews with management were conducted with businesses that have an EIS and plan to implement an EIS and thirdly, interviews with EIS-users in all levels of management were conducted. In stage one, the questionnaires were distributed via e-mail to all the listed JSE companies for the attention of executives and top management as per the Questionnaire Annexure (added as a supplementary file), a total of 334 listed JSE companies at the time of the study. In stage two, seven respondents from the questionnaire were selected to participate in the interview process to collect in-depth information regarding their company's EISs status. The questions and results are reflected as per the Interviews Annexure in Group A and Group B (added as a supplementary file). In stage three, one company was selected from stage two (companies with an EIS) that consists of EIS-users in different levels of management. Six interviews were conducted from the different management levels of the company as per the Interviews Annexure in Group C (added as a supplementary file). Questions asked in the interviews varied from structured questions to openended questions. The results collected from the interviews were documented and analysed as per the Interviews Annexure (added as a supplementary file); in addition, the background and general observations from the interviews of all the companies per group were analysed and explained.

\section{Findings}

The findings from each of these three stages made a contribution to the study. For the purpose of this study the emphasis was on companies with EISs and companies that plan to implement EISs. Findings on companies with no EIS were analysed but not disclosed in this article.

\section{Quantitative results: Questionnaires}

The survey data from the questionnaires provided useful insight into listed JSE companies who have already implemented EISs and for those who plan to implement EISs. The data confirmed, as per Table 1, that there is a growing interest in EISs. Of the 65 companies that responded, (a response rate of $19.5 \%$ ) $38.5 \%$ companies have currently implemented EISs and 20\% of the remaining companies plan to implement EISs. Companies responded as followed:

- Group 1 - Twenty-five companies with EISs

- Group 2 - Twenty-seven companies with no EISs

- Group 3 - Thirteen companies plan to implement EISs.

Of the 13 respondents who planned to implement an EIS in the future (in Table 2), 38.5\% of respondents planned to implement an EIS within one to two years, whilst both groups of $23.1 \%$ of the respondents planned to implement an EIS in 1 to 6 months and 6 to 12 months respectively. One respondent indicated that they wanted to implement an EIS in under 1 month.

Fifty two percent $(52.1 \%)$ of the respondent's software formed part of the standard package, which included EIS.

Table 4 indicates that the number of users that access EISs is higher for larger companies.

\section{Purposes for using Executive Information Systems}

Respondents could select more than one purpose for using EISs. Potentially an EIS fulfils a wide range of purposes but as per Table 5 only the main purposes were listed. 
The respondents could select more than one person as main users of EISs as per Table 6 .

There was definitely a significant relationship evident between decision-making and problem solving in Table 6 versus quality and integrity of information in Table 7.

Decision-making and problem solving scored the highest as the most important purposes of EISs as per Table 5 and therefore executives rated the quality $(35.4 \%)$ and integrity $(32.3 \%)$ of information as the most important criteria for the success of EISs. There is definitely a significant relationship visible between the challenges of EISs and the criteria for success of EISs regarding the decision-making and problem solving versus quality and integrity of information. The third most important criterion for the success of EISs is user-friendliness $(24.6 \%)$, followed by quick response time $(23.1 \%)$.

The criterion 'cost' was not a major factor for the success of EISs and the criterion 'interest of staff' was not even considered important by respondents. Surprisingly the criterion 'better communication amongst management' $(15.4 \%)$ was added as a last criterion to test the diversity of staff in current South African companies as well as the relationship of information technology developers versus users.

\section{Qualitative results: Interviews}

Seven executives from the respondents of the questionnaire were interviewed to determine how EISs or other information systems were used by executives and management and how the systems influenced the decision making process as per Group A and B. Six EIS-users were interviewed, as per Group $C$, in all levels of management. Interviews were conducted as follows:

1. Group A: Companies with EISs - Interviews with management of five companies.

2. Group B: Companies who plan to implement EISs Interviews with management of two companies.

3. Group C: Company with an EIS with extended availability to all levels of management - Interviews with six EISusers.

\section{Companies with Executive Information Systems: Results of Group A}

A successful EIS provides the executive with the necessary real-time information that is needed in decision-making and solving problems under time pressure. An EIS is a trusted source of information to be used as a management information tool for the companies. Companies had different software options for their EISs, the stand-alone off the shelf package was the most popular; EISs have been used for five years plus. The number of users accessing EISs varied from 26 to over 500 users. The accountant was the most prolific user. The three most ranked motivation factors were: to improve the effectiveness and efficiency of executives, to provide easier and faster access to information, and finally, to interface with other software. The five top-ranked purposes of EISs were:
TABLE 1: Existence of Executive Information Systems (EISs) in Johannesburg Stock Exchange companies.

\begin{tabular}{lll}
\hline Companies with an EIS & Frequency & Valid \% \\
\hline Yes & 25 & 38.5 \\
Yes, plan to implement an EIS & 13 & 20.0 \\
No & 27 & 41.5 \\
\hline Total & $\mathbf{6 5}$ & $\mathbf{1 0 0}$ \\
\hline
\end{tabular}

TABLE 2: Implementation time of Executive Information Systems (EISs) in the near future.

\begin{tabular}{lcc}
\hline Implementation time of an EIS & Frequency & Valid \% \\
\hline Less than 1 month & 1 & 7.7 \\
$1-6$ months & 3 & 23.1 \\
6-12 months & 3 & 23.1 \\
$1-2$ years & 5 & 38.5 \\
3-4 years & 1 & 7.7 \\
\hline Total & $\mathbf{1 3}$ & $\mathbf{1 0 0}$ \\
\hline
\end{tabular}

TABLE 3: Software for existing Executive Information Systems (EISs).

\begin{tabular}{lcc}
\hline Software for existing EISs & Frequency & Valid \% \\
\hline Part of the standard package which included an EIS & 13 & 52 \\
Hiring of external consultants to develop an EIS & 4 & 16 \\
Stand-alone off the shelf package & 3 & 12 \\
Own developed software & 2 & 8 \\
Other & 3 & 12 \\
\hline Total & $\mathbf{2 5}$ & $\mathbf{1 0 0}$
\end{tabular}

TABLE 4: Number of users accessing the complete Executive Information Systems (EISs).

\begin{tabular}{lcc}
\hline Number of users accessing the complete EISs & Frequency & Valid \% \\
\hline $26-50$ & 7 & 28 \\
$51-75$ & 5 & 20 \\
$76-100$ & 2 & 8 \\
$101-200$ & 3 & 12 \\
$201-500$ & 2 & 8 \\
$501+$ & 6 & 24 \\
\hline Total & $\mathbf{2 5}$ & $\mathbf{1 0 0}$ \\
\hline
\end{tabular}

TABLE 5: Purposes for using Executive Information Systems (EISs).

\begin{tabular}{lcc}
\hline Purposes for using EISs & \multicolumn{2}{c}{ Marked } \\
\cline { 2 - 3 } & Count & \% \\
\hline Decision-making & 24 & 36.9 \\
Problem solving & 15 & 23.1 \\
Quick reference & 8 & 12.3 \\
Scheduling & 6 & 9.2 \\
Electronic mail & 6 & 9.2 \\
Other & 3 & 4.6 \\
\hline Total & $\mathbf{6 5}$ & $\mathbf{1 0 0}$ \\
\hline
\end{tabular}

TABLE 6: Main users of Executive Information Systems (EISs).

\begin{tabular}{lcc}
\hline Main users of EISs & \multicolumn{2}{c}{ Marked } \\
\cline { 2 - 3 } & Count & $\mathbf{\%}$ \\
\hline Executive & 22 & 33.8 \\
Chief Executive Officer & 17 & 26.2 \\
Accountant & 15 & 23.1 \\
Manager & 13 & 20.0 \\
Management Information Services & 10 & 15.4 \\
Other & 3 & 4.6 \\
\hline Total & $\mathbf{8 0}$ & $\mathbf{1 2 3}$
\end{tabular}


TABLE 7: Criteria for the success of Executive Information Systems (EISs).

\begin{tabular}{|c|c|c|}
\hline \multirow[t]{2}{*}{ Criteria for the success of EISs } & \multicolumn{2}{|c|}{ Marked } \\
\hline & Count & $\%$ \\
\hline Quality of information & 23 & 35.4 \\
\hline Integrity of information & 21 & 32.3 \\
\hline User-friendly & 16 & 24.6 \\
\hline Quick response time & 15 & 23.1 \\
\hline Decision-making & 13 & 20.0 \\
\hline Regularly updated & 13 & 20.0 \\
\hline Management involvement & 12 & 18.5 \\
\hline Better communication amongst management & 10 & 15.4 \\
\hline Cost & 9 & 13.8 \\
\hline Other & 1 & 1.5 \\
\hline
\end{tabular}

1. trend analysis

2. drill down facility

3. critical success factors

4. exception reporting

5. quick and immediate access.

The following five factors of EISs were the most crucial to add strategic value within companies:

1. quality of information

2. response time

3. availability of regularly required information

4. availability of market indicators

5. viruses.

Companies identified the following areas to improve EISs:

- to handle volume of data faster

- accessing relevant information

- automated systems.

The EIS, the Internet and e-mail were the most popular media executives used to source information. All companies confirmed that EISs assisted in decision-making.

\section{Companies planning to implement Executive Information Systems: Results of Group B}

One company planned to implement an EIS over a sixmonth period as phase one and the other company had already implemented an EIS in six of its 13 operations. Both companies felt that the EIS would:

- improve the immediate availability of information and the drill down to transaction level

- provide a system that is user-friendly

- decrease the working days substantially to produce consolidated Group results

- increase the strategic value for decision making and immediate problem solving.

The EIS is supported and empowered by the Chief Executive Officers (CEOs), Financial Directors (FDs) and Company Secretary (CS). Both the interviewees seek quicker, better and more efficient ways to do their day-to-day activities and produce timeous reports. Both companies use software that is part of a standard package. The implementation of an EIS is seen as being able to enhance the communication capabilities and improve the existing database of the company.
Company with an Executive Information Systems with extended availability to all levels of management: Results of Group C

All staff at all levels use the EIS on a daily basis, except for Junior Management staff who use the EIS monthly. The EIS enhances the positions of all staff members to add strategic value to the company by making decisions and solving problems much quicker, by identifying which business unit is performing or not, by extracting relevant trend analysis, by reducing the amount of paper-based reports, by managing the business effectively and by allowing quick and immediate access to up-to-date information. Different kinds of information are extracted from the EIS and vary from each management level. All the staff, at all levels of management, agreed that the EIS supports their day-to-day activities. Extracted information from the EIS is used differently in each category and varied from, amongst others:

- reporting to the Executive Committee and the Board

- running and managing the business

- answering queries

- confirming data and/or information

- making decisions

- sharing information and planning for future developments.

All staff members confirmed that there were areas to improve their EIS; for example, to be able to slice and dice information, to create a 'what if' analysis, to provide timeous provision of results, to improve the accuracy of information, to view a single customer, to centralise data, to navigate data, and to locate data logically.

\section{Limitations of the study}

The most crucial part of the empirical study was that questionnaires were limited to the top management and executives.

The following issues had an impact on the response rate of the questionnaires:

- Executives were out of office for a long period of time and reminders were sent out more than once.

- The mailing list with e-mail addresses was obtained from McGregor BFA. A few e-mail addresses were not included; therefore e-mail addresses were obtained from websites and telephonically. The Internet only provides general contact information e-mail addresses and not the e-mail addresses of CEOs, FDs, Managing Directors (MDs), directors and executives; therefore questionnaires were only e-mailed to the general information contact e-mailed addresses. Recipients of these e-mails were asked to forward the questionnaires to the addressed CEOs, FDs, MDs, directors or executives as per the mailing list.

- Nonrespondents that had no websites were contacted telephonically, but in some cases the telephone numbers were incorrect.

- Some listed JSE companies obtained from McGregor BFA were delisted or suspended.

- Some addressees e-mailed the sender directly without completing the questionnaire. 
- Some listed JSE companies were contacted telephonically and phone calls were forwarded to the personal assistants (PAs) of the CEOs, FDs, MDs, directors or executives as they informed the author that their superiors do not participate in surveys or were unable to complete the survey as a result of time constrictions.

- A few JSE companies were not in the position to disclose the name or e-mail address of the CEOs, FDs, MDs, directors and executives telephonically.

- The McGregor mailing list did not include the most recent executives, as the annual reports of firms were only made available after the firm's financial year-end. Executives listed in the annual report at year-end already left the firm although the information needed by McGregor for their mailing list was obtained from the annual reports.

In addition, the research is limited to listed JSE companies in South Africa. The results are therefore only applicable to South Africa, but can be applied to other businesses that are not listed in South Africa.

\section{Conclusion}

From the findings of the study it was evident that companies view an EIS as an excellent management information tool which makes use of standard tools and built-in features that is critical for real-time decision-making, solving problems, creating a competitive edge and adding strategic value to companies. The speed of the decision-making process definitely increases the rapidity of problem identification since EISs are used by executives, top management and managers. Companies all confirmed that EISs could be of assistance in the decision-making process. The main reasons motivating companies to plan implementing an EIS include the following:

- major expansions in the company

- to improve the immediate availability of information

- a drill down facility to transaction level

- user-friendliness

- to decrease working days substantially to produce consolidated group results

- quicker and better ways to improve their daily routine and/or reduce or eliminate paper-based reports.

Companies confirmed that using an EIS as a management information tool, added value to their business, which contributed to the objectives of the study to understand the challenges presented by EISs in listed JSE companies.

\section{Recommendations for future research}

The research provides guidance for future research, as this study was to establish the existence of and challenges implicit in EISs in listed JSE companies. Furthermore the study also intended to explore the reasons why listed JSE companies do not have an EIS. Several respondents to the questionnaires and interviewees requested a report on the outcome of the results. As users need systems as an on-going process that provide access to diverse types of information there is therefore a need for continued research in the area of future EIS implementations and to document successful EIS development.

\section{References}

Arnott, D., Jirachiefpattana, W. \& O'Donnell, P., 2007, 'Executive information systems development in an emerging economy', Decision Support Systems 42(4), 20782084. doi:10.1016/j.dss.2004.11.010

Averweg, U.R. \& Roldán, J.L., 2006, 'Executive information system implementation in organisations in South Africa and Spain: A comparative analysis', Computer Standards \& Interfaces 58(6), 625-634. doi:10.1016/j.csi.2005.06.001

Bajwa, D.S., Rai, A. \& Brennan, I., 1998, 'Key antecedents of executive information system success: A path analytic approach', Decision Support Systems 22(1), 31-43. doi:10.1016/S0167-9236(97)00032-8

Bergeron, F., Raymond, L., Rivard, S. \& Gara, M-F., 1995, 'Determinants of EIS use: Testing a behavioural model', Decision Support Systems 14(2), 131-146. doi:10.1016/0167-9236(94)00007-F

Bocij, P., Chaffey, D., Greasley, A. \& Hickie, S., 2003, Business information systems: Technology, development and management for the e-business, 2nd edn., PrenticeHall, Harlow, UK.

Boddy, D., Boonstra, A. \& Kennedy, G., 2005, Managing information systems: An organisational perspective, 2nd edn., Pearson, Harlow, UK.

Boone, L.E. \& Kurtz, D.L., 2006, Contemporary Business 2006, Thomson, Mason, USA.

Braman, S., 1989, 'Defining information: an approach for policymakers', Telecommunications 13, 233-242. doi:10.1016/0308-5961(89)90006-2

Burgelman, R.A., Christensen, C.M. \& Wheelwright, S.C., 2004, Strategic Management of technology and innovation, McGraw-Hill, Singapore.

Burgelman, R.A. \& Doz, L.D., 2004, 'The power of strategic integration' in R.A. Burgelman, C.M. Christensen \& S.C. Wheelwright (eds.), Strategic management of technology and innovation, pp. 1174-1181, McGraw-Hill, Singapore.

Byrd, T.A. \& Marshall, T., 1996, 'Corporate culture, related chief executive officer traits, and the development of executive information systems', Computers in Human Behaviour 12(3), 449-464. doi:10.1016/0747-5632(96)00018-0

Cash, J.I., Mcfarlan, F.W. \& Mckenney, J.I., 1992, 'Corporate information systems management', 3rd edn., Irwin, IL.

Cheung, W. \& Babin, G., 2006, 'A metadatabase-enabled executive information system (Part A): A flexible and adaptable architecture', Decision and Support Systems 42, 1589-1598. doi:10.1016/j.dss.2006.01.005

Clark, T.D. Jr, 1994, 'Corporate systems management' in R.D. Galliers \& B.S.H. Baker (eds.), Strategic Information Management, pp. 29-51, Butterworths-Heinemann, Oxford, UK.

Correia, Z. \& Wilson, T.D., 1997, 'Scanning the business environment for information: a grounded theory approach', Information Research 2(4), viewed 27 June 2006 , from http://www. informationr.net/ir/2-4/paper21.htm

Cramm, S., 2010, 'Helping Businesses help themselves', Harvard Business Review November, 124.

Elam, J.J. \& Leidner, D.G., 1995, 'EIS adoption, use, and impact: the executive perspective', Decision Support Systems 14(2), 89-103. doi:10.1016/01679236(94)00004-C

Frolick, M.N. \& Robichaux, B.P., 1995, 'EIS information requirements determination: Using a group support system to enhance the strategic business objectives method', Decision Support Systems 14(2), 157-170.

Friend, D., 1992, 'EIS and the collapse of the information pyramid' in H.J. Watson, R.K. Rainer \& G. Houdeshel, Executive Information Systems: Emergence, Development, Impact, pp. 327-335 Wiley, New York.

Frolick, M.N. \& Robichaux, B.P., 1995, 'ElS information requirements determination: Using a group support system to enhance the strategic business objectives method', Decision Support Systems 14(2), 157-170. doi:10.1016/01679236(94)00009-H

Grindley, K., 1991, Managing IT and board level, Pitman, London, UK.

Hall, J.A., 2007, Accounting Information Systems, 5th edn., Thomson, Mason, USA.

Ikart, E.M., 2005, 'Executive information systems and the top-officers' roles: An exploratory study of user-behaviour model and lessons learnt', Australian Journal of Information Systems 13(1), 78-100.

Khan, S.J., 1996, 'The benefits and capabilities of executive information systems', MBA dissertation, University of the Witwatersrand, Johannesburg, South Africa.

Klenke, K., 1993, SIGCPR Annual conference, changing roles of information systems professionals: From technical managers to strategic leaders, ACM, New York.

Lessing, N. \& Scheepers, C., 2004, Information is a management issue, 9th edn., CSIC Publishers, Johannesburg.

Martin, E.W., Dehayes, D., Hoffer, J.A. \& Perkins, W.C., 2005, Managing information technology, 5th edn., Pearson, Upper Saddle River, NJ.

Martin, E.W., Dehayes, D., Hoffer, J.A. \& Perkins, W.C., 1994, Managing information technology: What managers need to know, 2nd edn., Macmillan, New York.

Mcleod, R. Jr \& Jones, J.W., 1992, 'Making executives information systems more effective', in H.J. Watson, R.K. Rainer \& G. Houdeshel, Executive Information Systems: Emergence, Development, Impact, pp. 53-69, Wiley, New York. 
Meyer, H.W.J., 2005, 'The nature of information, and the effective use of information in rural development', Information Research 10(2), 214-225.

Meyer, T., 2011, 'The art of strategy what CEOs need to know', Accountancy SA, December 2010 - January 2011, 50-51.

Mintzberg, H. \& Waters, J.S., 1990, 'Studying deciding: An exchange of views between Mintzberg and Waters, Pettigrew, and Butler', Organizational Studies 11(1), 1-16. doi:10.1177/017084069001100101

Mintzberg, H., 1975, 'The managers' job: Folklore and fact', Harvard Business Review, July-August, 49-61.

Naicker, D., 2010, 'CFO Responsibilities in an emerging market', Accountancy SA, September, 21.

Nichols, G.E., 1990, 'On the nature of Management Information' in R. Galliers, Information Analysis, pp. 7-17, Addison-Westley, Sydney.

Nieman, G. \& Bennett, A., 2002, Business management, Van Schaik, Pretoria.

Nord, J.H. \& Nord, G.D., 1995, 'Executive information systems: A Study and comparative analysis', Information \& Management 29(2), 95-106. doi:10.1016/0378 7206(95)00013-M

Olson, D.L. \& Courtney, J.F., 1992, Decision support models and expert systems, Macmillan, New York.

Palvia, P., Kumar, A., Kuma, N. \& Hendon, R., 1996, 'Information requirements of a global EIS: An exploratory macro assessment', Decision Support Systems 16(2), 169-179. doi:10.1016/0167-9236(95)00005-4

Phillips, K., 2011, 'To Liberate Accountants first empowers the business', Accountancy SA, December 2010 - January 2011, 37.

Pitts, A. \& Lei, D., 2003, Strategic Management: Building and sustaining competitive advantage, Thomson, Canada.

Pijpers, G.G.M., Bemelmans, T.M.A., Heemstra, F.J. \& Van Montfort, K.A.G.M., 2001 'Senior executive' use of information technology', Information and Software Technology 43(15), 959-971. doi:10.1016/S0950-5849(01)00197-5

Porter, M., 1996, 'What is strategy?', Harvard Business Review, November-December $61-78$.

Prokesch, S.E., 2000, Harvard Business Review: Interviews with CEOs: Unleashing the power of learning, 5 th edn., Harvard Business School, Boston, MA.

Rainer, R.K. \& Watson, H.J., 1995, 'What does it take for successful executive information system?', Decision Support Systems 14(2), 147-156. doi:10.1016/01679236(94)00008-G

Remenyi, D.S.J., 1991, Introduction strategic information systems planning, NCC Blackwell, Oxford, UK.

Salmeron, J.L., 2002, 'EIS date: findings from an evolutionary study', The Journal of Systems and Software 64(2), 111-114. doi:10.1016/S0164-1212(02)00030-4
Salmeron, J.L., 2003, 'EIS success: keys and difficulties in major companies', Technovation 23(1), 35-38. doi:10.1016/S0166-4972(01)00076-1

Simons, R., 2010, 'Stress-Test your strategy', Harvard Business Review, November, 92-100.

Singh, S.K., Watson, H.J. \& Watson, R.T., 2002, 'ElS support for the strategic management process', Decision Support Systems 33(1), 71-85. doi:10.1016/ S0167-9236(01)00129-4

Stephenson, B.Y., 1986, 'Information: A strategic business weapon: DSS-86 Transactions', Sixth international conference on Decision Support Systems, edited by J. Fedorowicz, College on Information Systems, Washington, DC.

Sterrenberg, G.K., 1990, 'The structure of executive information systems', MBA dissertation, University of the Witwatersrand, Johannesburg, South Africa.

Turban E, Mclean, E. \& Wetherbe, J., 1996, Information technology for management, Wiley, Toronto.

Typanski, R.E., 1999, 'Creating an effective information environment', Information Systems Management 16(2), 32-39. doi:10.1201/1078/43188.16.2.19990301/3 1174.6

Van Zyl, J., 2010, 'More than a gut feeling', Finweek, 11 November 2010, 12.

Volonino, L., Watson, H.J. \& Robinson, S., 1995, 'Using EIS to respond to dynamic business conditions', Decision Support Systems 14(2), 105-116. doi:10.1016/01679236(94)00005-D

Voogt, T., 2010, 'IT Governance Dear CFO what should we do?', Accountancy SA October, 28-30.

Watson, H.J., Watson, R.T., Singh, S. \& Holmes, D., 1995, 'Development practices for executive information systems: Findings of a field study', Decision Support Systems 14(2), 171-184. doi:10.1016/0167-9236(94)00010-P

Watson, H.J., 1992, 'Avoiding hidden EIS pitfalls a case study: What you see isn't always what you get', in H.J. Watson, R.K. Rainer \& G. Houdeshel, Executive Information Systems: Emergence, Development, Impact, pp. 237-244, Wiley, New York.

Wessels, P.L., 2008, 'The identification and discussion of strategies for implementing an IT skills framework in the education of professional accountants', SA Journal of Accounting Research 22(1), 147-172.

Wheeler, F.P., Chang, S.H. \& Thomas, R.J., 1993, 'Moving from EIS to everyone's information system: Lessons from a case study', Journal of Information Technology 8, 177-183. doi:10.1057/jit.1993.24

Xu, X.M. \& Kaye, G.R., 2002, 'Knowledge workers for information support: Executives' perceptions and problems', Information Systems Management 19(1), 81-90. doi: 10.1201/1078/43199.19.1.20020101/31480.11

Young, D. \& Watson, H.J., 1995, 'Determinants of EIS acceptance', Information \& Management 29(3), 153-164. doi:10.1016/0378-7206(95)00011-K 